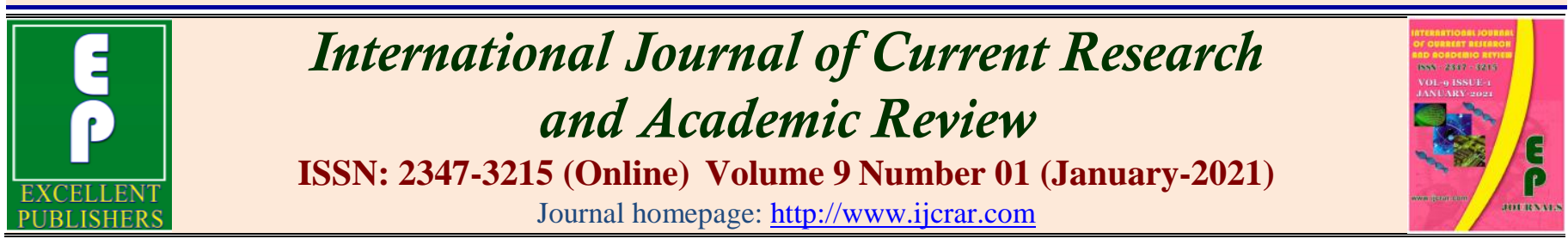

doi: https://doi.org/10.20546/ijcrar.2021.901.006

\title{
Study on Prevalence and Major Species Identification of Ixodidae Ticks of Bovine in Soddo Zuria Districts of Wolayta Zone in Southern Nation Nationalities and People's Region
}

\author{
Dereje Darza $^{1}$ Asrat Ayza $^{2}$ and Birhanu Lencha Kiffo ${ }^{2}$ \\ ${ }^{1}$ Haramaya University, College of Veterinary Medicine, Ethiopia \\ ${ }^{2}$ Wolaita Sodo University, College of Agriculture, Ethiopia \\ *Corresponding author
}

\begin{abstract}
A cross-sectional study design was conducted from November 2019 to April 2020 to identify the major ixodidae tick species and their prevalence in Sodo Zuria districts of Wolaita Zone in SNNPR of Ethiopia. A total of 3287(1701 male and 1586 female) adult ixodid ticks were collected from 500 animals during the study period. In this study three genera/sub-genus; Amblyomma, Rh. (Boophilus) and Rhipicephalus and four species were identified. From the three genera Amblyomma takes highest prevalence (45.29\%). From four species identified, two of them belong to genus Amblyomma; Amblyomma variegatum and Amblyomma cohaerence, one Boophilus; Boophilus decoloratus and one Rhipicephalus; Rhipicephalus evertsievertsi. The quantitative hierarchy of the tick species was Rh. evertsi (14.40\%), A. cohaerence (17.60\%), A. variegatum $(27.66 \%)$ and $B$. decoloratus $(40.34 \%)$ in ascending order. Therefore, the result indicated that B. decoloratus $(40.34 \%)$ and $A$. variegatum $(27.66 \%)$ are the most abundant tick species of cattle in Sodo Zuria districts. Except B. decoloratus of which more females than male were collected, the number of male ticks counted were exceed those of female. The result of this study also demonstrated a significance variation $(\mathrm{p}<0.05)$ on infestation between local, cross and exotic breed cattle's with highest prevalence in exotic breeds (75\%), than both cross $(56.2 \%)$ and local $(68 \%)$ breeds and poor body conditioned cattle's. Although a comparatively higher infestation was found on animals $>4$ years compared with $\leq 4$ year ones and between females than males and the difference was not statistically significant $(\mathrm{p}>0.05)$. Acaricide application was the main tick control method in the study area. Thus strategic application of acaricides might minimize the burden of ticks on the cattle of the study area.
\end{abstract}

\section{Introduction}

Ethiopia has one of the largest livestock inventories in Africa with a national cattle herd estimated to be about 53.99 million. Out of this total cattle population, the female cattle constitute about $55.48 \%$ and the remaining $44.52 \%$ are male cattle. On the other hand, the results

\section{Article Info}

Accepted: 08 December 2020

Available Online: 20 January 2021

Keywords

Cattle, Genus, Ixodidae ticks, Prevalence, Sodo Zuria, Species. 
than $85 \%$ of farm cash income (Befekadu and Birhanu, 2000).

Ticks belong to the phylum Arthropod, class Arachnid, and order Acari. Ticks are usually relatively large and long lived, compared to mites, surviving for up to several years and highly specialized group of obligate, blood sucking, nonpermanent ectoparasitic arthropods that feed on mammals, birds and reptiles (Kettle, 1995). They have been recognized as the notorious threat due to severe irritation, allergy and toxicosis, and also known to transmit diseases like Babesiosis, theileriosis, anaplasmosis, in man and animals etc. (Niyonzema and Kiltz, 2007; Norval et al., 2007). Moreover their effects lead to economic losses, such as lower performance, increased mortality, and reduced meat and milk production (Byford et al., 1992; Niyonzema and Kiltz, 2007).

Among ectoparasites, the families of ticks parasitizing livestock are categorized into two, the Ixodidae (hard ticks) and Argasidae (soft ticks). Though, sharing certain basic properties, they differed in many structures, behavioral, physiological, feeding and reproduction pattern (Urquhart et al., 1996). The family Ixodidae (hard ticks) are characterized by the presence of a rigid chitinous Scutum, which covers the entire dorsal surface of the adult male, in the female and in the larva and in the nymph, it extends for only small areas(one third of the body) which permit the abdomen to swell after feeding (Kettle, 1995). The Argasidae (soft tick), lacks Scutum. There is only one Argasidaetick recorded in Ethiopia which is Argaspersicus also known as "fowl tick" that has been recorded and widely spread in the country (Walker et al., 2003).

The importance of ticks as a vector in human and domestic animals has attracted the attention of large workers all over the world (Hoogstral, 1979). It has been estimated that about $80 \%$ of the world population of cattle are infested with ticks. The life cycle of ticks (both Ixodids and Argasids) undergo four stages in their development; eggs, 6-legged larva, 8-legged nymph and adult (Lefebvre et al., 2010; Minjauw and McLeod, 2003).

According to the numbers of hosts, Ixodids ticks are classified as one-host ticks, two-host ticks, three-host ticks and Argasids classified as multi-host ticks. In onehost ticks, all the parasitic stages (larva, nymph and adult) are on the same hosts; in two- host ticks, larva attach to one host, feed and moult to nymphal stage and engorged, after which they detach and moult on the ground to adult; and in three-host ticks, the larva, nymph and adult attach to different hosts and all detach from the host after engorging, and moult on the ground. In multihost ticks (Argasids), a large number of hosts are involved and it is common to have five moults, each completed after engorging and detaching from the hosts (Taylor et al., 2007).

Ticks that are considered to be most important to domestic animals' health in Africa comprise about seven genera and forty species. Among these tick genera, the main ticks found in Ethiopia are Ambylomma (40\%), Boophilus (21\%), Heamaphysalis (0.5\%), Haylomma (1.5\%), and Rhipicephalus (37\%) (De Castor, 1997; Minjauw and McLeod, 2003). Among these, A. variegatum and $B$. decoloratusare most important and widely distributed (Abebaw, 2004). A. cohaerence, A. gemma, A. lepidium, Haylomma marginatum rufipes, $H$. truncatum, and $R$. evertsiare also commonly found in Ethiopia (Solomon and Kaaya, 1996; Pegram et al., 2004).

The impact of ticks and tick borne diseases (TBDs) on the individual and national economics warrants application of appropriate tick control strategies on priority basis (Bansal, 2005). The successful implementation of rational and sustainable tick control programs in grazing animals is dependent upon a sound knowledge of the epidemiology of the parasite due to interaction with the host in specific climate, management and production environments. In some countries substantial ecological and epidemiological knowledge bases have been established through extensive studies and field trials. On the contrary developing countries lack such information due to sufficient human, economic and infrastructural resources (FAO, 2004).

Acaricide application is still the main method of tick control in Ethiopia. Arsenicals and chlorinated hydrocarbons have been banned because of the threat to human health and the emergence of acaricide resistance against economically important species of tick (Newson and De Castro, 1993). Currently organophosphate is the most widely used chemical although evidence of resistance is emerging. Amides and pyrethroids have recently been introduced, while plants that have acaricide properties are widely used for tick control in rural areas (Mekonnen, 1998).Therefore, the objectives of this study were to: Identify the common tick species and their prevalence in Sodo Zuria Woreda and To assess the association of different risk factors with respect to tick prevalence. 


\section{Materials and Methods}

\section{Description of study area}

The tick survey was conducted in south nation nationalities and peoples' region of Wolaita Zone particularly, in Sodo Zuria woreda from November, 2019 to April, 2020. The town is located $380 \mathrm{~km}$ southwest of Addis Ababa on the way to Arbamich town and it has a latitude and longitude of $6^{\circ} 54^{\prime} \mathrm{N} 37^{\circ} 45^{\prime} \mathrm{E}$ with an elevation between 1650 and 2980 meters above sea level. The mean annual temperature and relative humidity of the area are $19^{\circ} \mathrm{c}$ and $34 \%$ respectively. The town is bounded with Damot Gale Woreda to the North East, Humbo Woreda to the South East, Damot Weyde Woreda to East, Damot Sore Woreda to the North West, Boloso Sore Woreda to the North, Offa Woreda to the Southwest and Kindo Koysha to the East. The annual rain fall of the area is $1000-1200 \mathrm{~mm}$. The dry season extends from September to February and the rainy season stay from March to August.

The human population in the area is 162,691 ; which was 80,002 males and 82,689 females; none of its population are urban dwellers. The major crops grown the study area are cereals such as teff, maize, sorghum, and root crops like sweet potatoes, enset, carrot and fruits like mango, avocado and banana (,WSDADO, 2013)..

\section{Study population}

The target animals were bovine species found in selected kebeles of Soddo Zuria Woreda and these animals were constituted in all breeds but the mostly populated breed in the area was indigenous or local breeds which kept under traditional management system and were categorized based on their sex, age, breed and body conditions. The livestock population of the area comprised about 1,097,710 cattle; 150,383 sheep; 185,250 goats; 60,055 equines and 734,924 poultry (WSDADO, 2013).

\section{Study design}

A cross sectional study was conducted from November, 2013 to April, 2014 to determine prevalence of common adult hard tick (Ixodidae), to identify common tick species and to assess the association of different risk factors with respect to tick prevalence in cattle. All the animals selected as sampling unit were checked for any tick infestation based on the numbers of ticks found on the animal during the study period were recorded.
Ticks were collected from ears, heads, dewlaps, belly/flunk, udder/scrotum, perineum and legs/tails in the separated sample bottles with $70 \%$ ethanol. In addition to predilection sites, the burden of ticks based on age, sex, body condition and breeds of animals were determined.

\section{Sampling method and sample size determination}

The names of kebeles (6-kebeles), and the cattle to be examined were selected by simple random sampling method, and the sample size was determined by using the formula given in Thrust field (2005). The expected prevalence of ticks of cattle in Sodo Zuria woreda was assumed as $70 \%$. The parameters taken were $95 \%$ confidence interval and 5\% desired level of precision. By substituting these values in the formula, the sample size taken was, $n=323$, but to accurate (to increase the probability of estimating the actual population prevalence) the study I increased my sample size to 500 .

$\mathrm{n}=1.96^{2} \frac{\operatorname{Pexp}}{\mathrm{d}^{2}}(1-\underline{\text { Pexp }})$

Where $\mathrm{n}=$ sample size $; \mathrm{P}_{\exp }=$ expected prevalence $\mathrm{d}^{2}=$ expected precision which is usually $5 \%(0.05)$.

\section{Study methodology}

First the selected study animal was properly restrained and all tick samples were collected from half the body regions. Tick collection was performed using blunt steel forceps, by thorough examination of the entire body surface of the animals. Ticks from each animal were stored separately in vials containing $70 \%$ ethanol, labeled with information on the host (i.e., sample number, age), village, and date of sampling, then transport to WolaytaSoddo Regional Veterinary Laboratory for counting and identification. The ticks were counted and subsequently identified to genus and species level by using stereomicroscope, according to standard identification keys given by Walker et al. (2003). The equipment's and tools used during study were universal bottles, steel forceps, petridish, 70\% ethanol, gloves and stereomicroscope.

\section{Data analysis and interpretation}

All the data recorded in this study were enter into Microsoft excel and were subsequently be analyzed using computer software of SPSS version 16. The overall prevalence of tick was determined by dividing the number of positive animals by total sample size, and 
expressed as percentage. Chi-square test was used to assess statistically significant association in tick infestation between ages, sex, body condition and breeds. For this analysis $\mathrm{p}<0.05$ was considered as statistically significant whereas $\mathrm{p}>0.05$ considered statistically nonsignificant association between variables.

\section{Results and Discussions}

\section{Prevalence of ticks on cattle in Soddozuria woreda}

A total of 3287 ixodid ticks (1701 males and 1586 females) were collected from 500 cattle, comprising 319 local, 137 cross, and 44 exotic breeds. Three tick genera (i.e., Amblyomma, Rhipicephalus, and the Boophilus subgenus) and 4 species were identified.

The overall prevalence was calculated by dividing the numbers of positive samples by the total sample size and multiplied by 100 . Out of the 500 animals examined, ticks were found on 333 animals yielding an overall prevalence of $66.6 \%$ (Fig. 1; Table 1 and 2).

\section{Prevalence of ticks in relation to hypothesized risk factors}

The statistical analysis was done for the prevalence of tick infestation with hypothesized risk factors (age, sex, breed and body condition). There were statistically significant association with body condition $\left(\mathrm{x}^{2}=24.012\right.$, $\mathrm{p}=0.000)$ and breeds $\left(\mathrm{x}^{2}=12.039, \mathrm{p}=0.002\right)$ (Table $5 \& 6)$.

Higher tick infestation rate was seen on exotic breeds than local and cross breed animals. There were no statistical significances $(\mathrm{p}>0.05)$ association between age and sex groups (Table 3 and 4 ).

\section{Distribution of ticks species in half body regions of animals}

The observed proportion of tick species attachment site during this study was summarized and shown in table 7 . Both two species of Ambylomma identified during the study preferred head, legs/tail, belly/back, dewlap/brisket, perineum, and udder/scrotum regions. The Boophilus decolaratus preferred the attachment site such as, ears, heads, and perineum, legs/tail, belly/back udder/scrotum, dewlap/brisket regions in ascending order. Mainly the Rhipicephalus encountered from legs/tail, belly/back, ear, udder/scrotum, dewlap, perineum regions.

\section{Prevalence and sex ratio of tick species in the study area}

Of the total 3287 Ixodidticks collected from seven body region of 500 cattle's, four different species in three genera/sub-genus were identified. The tick species identified were Rhipicephalus evertsievertsi (14.35\%), Amblyomma cohaerence (17.60\%), Amblyomma variegatum (27.66\%), and Boophilus decolaratus $(40.34 \%)$ in ascending order of abundance (Table 8).

By considering relative abundance of each tick species identified in the study area, Boophilus decolaratuswas the most abundant (40.34\%) and Rhipicephalus evertsi subspecies evertsi was the least abundant (14.35\%).

Table.1 Overall prevalence of tick infestation

\begin{tabular}{|c|c|c|}
\hline Result & Amount & Prevalence \\
\hline Infested & 333 & $66.6 \%$ \\
\hline Non-infested & 167 & $33.4 \%$ \\
\hline Total & $\mathbf{5 0 0}$ & $\mathbf{1 0 0 \%}$ \\
\hline
\end{tabular}


Table.2 Distribution of tick genera/Sub-genus of cattle in the study area

\begin{tabular}{lllllllll}
\hline & \multicolumn{9}{l}{ Tick genus/sub-genus } \\
\cline { 2 - 9 } \multicolumn{1}{l}{ Kebeles } & Amblyomma & \multicolumn{2}{l}{ Rh.(Boophilus) } & \multicolumn{2}{l}{ Rhipicephalus } & Total & \\
\hline WachigaBusha & 277 & 44.89 & 267 & 43.27 & 73 & 11.83 & 617 & 18.77 \\
Waraza Lasho & 275 & 49.28 & 213 & 38.17 & 70 & 12.54 & 558 & 16.97 \\
Gulgula & 279 & 43.86 & 274 & 43.08 & 83 & 13.05 & 636 & 19.34 \\
DalbboAtiwaro & 198 & 37.07 & 254 & 47.56 & 82 & 15.35 & 534 & 16.24 \\
Offa Gandeba & 262 & 50.48 & 172 & 33.14 & 85 & 16.37 & 519 & 15.78 \\
BugeWanche & 198 & 46.80 & 146 & 34.51 & 79 & 18.67 & 423 & 12.86 \\
$\quad$ Total & $\mathbf{1 4 8 9}$ & $\mathbf{4 5 . 2 9}$ & $\mathbf{1 3 2 6}$ & $\mathbf{4 0 . 3 4}$ & $\mathbf{4 7 2}$ & $\mathbf{1 4 . 3 5}$ & $\mathbf{3 2 8 7}$ & $\mathbf{1 0 0 . 0 0}$ \\
\hline
\end{tabular}

Table.3 Prevalence of ticks in relation to age of animals

\begin{tabular}{lllc}
\hline Age & & & \\
\hline & $\leq 4$ years & >4years & Total \\
\hline Infested animals & 115 & 218 & 333 \\
non infested & 68 & 99 & 167 \\
Total & $\mathbf{1 8 3}$ & $\mathbf{3 1 7 5 0 0}$ & \\
\hline$\left(\mathrm{X}^{2}=1.833, \mathrm{P}=0.176\right)$ & & &
\end{tabular}

Table.4 Prevalence of ticks in relation to sex of animals

\begin{tabular}{|c|c|c|c|}
\hline \multicolumn{4}{|c|}{ Sex } \\
\hline & Male & Female & Total \\
\hline Infested animals & 146 & 187 & 333 \\
\hline non infested & 74 & 93 & 167 \\
\hline Total & 220 & 280500 & \\
\hline
\end{tabular}

$\left(X^{2}=0.010, P=0.921\right)$

Table.5 Prevalence of ticks in relation to body condition of animals

\begin{tabular}{lllll}
\hline Body Condition & & & & \\
\hline & Poor & Medium & Good & Total \\
\hline Infested animals & 136 & 130 & 67333 & \\
non infested & 40 & 62 & 65 & 167 \\
Total & $\mathbf{1 7 6}$ & $\mathbf{1 9 2}$ & $\mathbf{1 3 2}$ & $\mathbf{5 0 0}$ \\
\hline$\left(\mathrm{X}^{2}=24.012, \mathrm{P}=0.000\right)$ & & & &
\end{tabular}

Table.6 Prevalence of ticks in relation to breed of animals

\begin{tabular}{llllll}
\hline Breed & \multicolumn{1}{l}{ Local } & Cross & Exotic & Total \\
\hline & 220 & 77 & 36 & 333 & \\
\hline Infested animals & 99 & 60 & 8 & 167 \\
non infested & $\mathbf{3 1 9}$ & $\mathbf{1 3 7}$ & $\mathbf{4 4}$ & $\mathbf{5 0 0}$ \\
Total & & & & &
\end{tabular}


Table.7 Numbers of tick species identified in half body regions of cattle

\begin{tabular}{llllllll}
\hline \multirow{2}{*}{ Tick species } & \multicolumn{6}{l}{ Body Regions } \\
\cline { 2 - 7 } & Head & Ear & Dewlap & Legs/tail & Udder/scrotum & Perineum & Belly \\
\hline A.variegatum & 52 & - & 358 & 55 & 296 & 110 & 38 \\
A.cohaerence & - & - & 75 & - & 255 & 160 & 90 \\
B.decolaratus & 64 & 61 & 513 & 119 & 377 & 60 & 132 \\
R.evertsi-evertsi & - & 54 & 112 & 21 & 80 & 175 & 30 \\
Total & $\mathbf{1 1 6}$ & $\mathbf{1 1 5}$ & $\mathbf{1 0 5 8}$ & $\mathbf{1 9 5}$ & $\mathbf{1 0 0 8}$ & $\mathbf{5 0 5}$ & $\mathbf{2 9 0}$ \\
\hline
\end{tabular}

Table.8 The distribution and sex ratio of adult tick species in the study area

\begin{tabular}{llllll}
\hline Tick species & Total & Prevalence (\%) & \multicolumn{2}{c}{ Sex } & Ratio \\
\cline { 4 - 5 } & count & & Male & female & (male: female) \\
\hline R.evertsi-evertsi & 472 & 14.40 & 410 & 62 & $6.6: 1$ \\
A.cohaerence & 580 & 17.60 & 500 & 80 & $6.2: 1$ \\
A.variegatum & 909 & 27.66 & 13 & 1313 & $009: 1$ \\
B.decoloratus & 1326 & 40.34 & 778 & 131 & $5.9: 1$ \\
Total & $\mathbf{3 2 8 7}$ & $\mathbf{1 0 0 . 0 0}$ & $\mathbf{1 7 0 1}$ & $\mathbf{1 5 8 6}$ & $\mathbf{1 . 0 7 : 1}$ \\
\hline
\end{tabular}

Fig.1 Tick species encountered during study period

A)

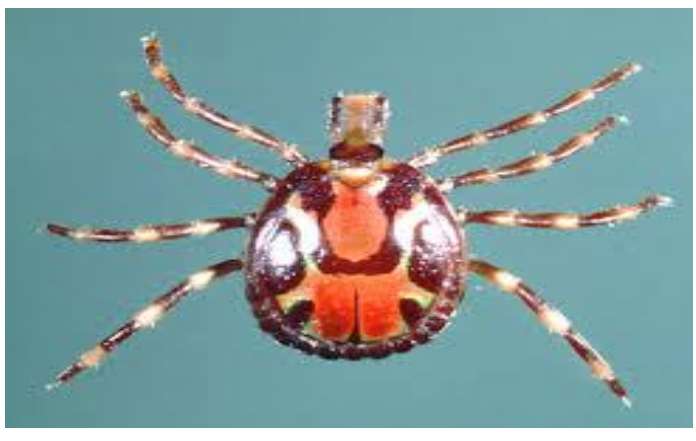

C)

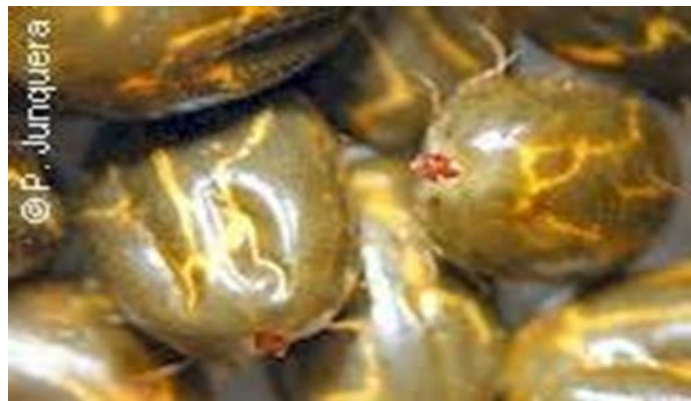

B)

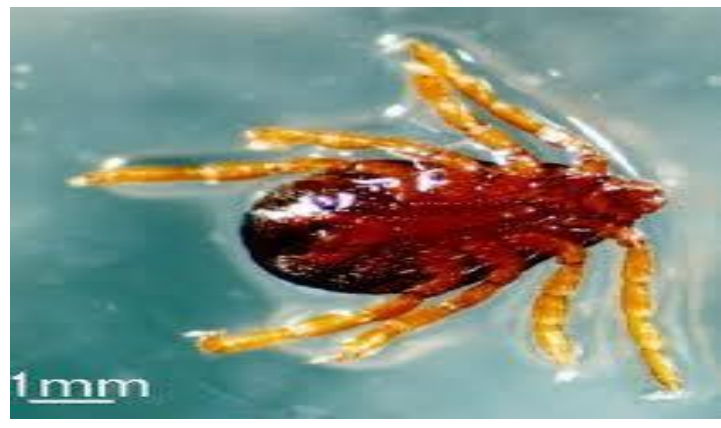

D)

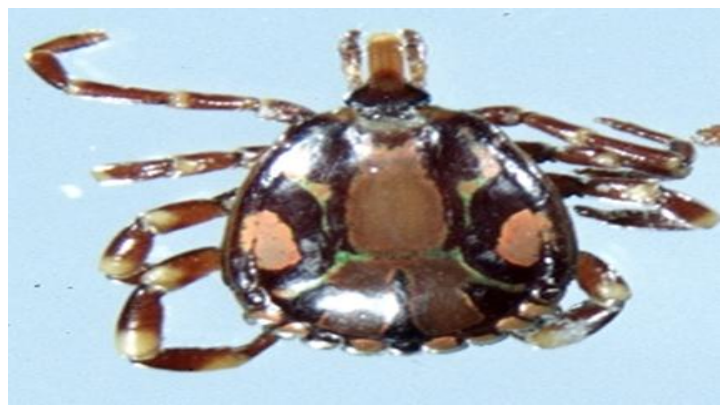

A) Amblyommavariegatum B)Rhipicephalusevertsievertsi C) Rhipicephalus (Boophilus) decoloratus D)Amblyommacohaerence.

Source: https://www.google. Tick photos com/search accessed on (05/12/2014). 
In this survey a total of 3287 ticks were collected from a total of 500 local, cross and exotic breeds of animals and the overall prevalence was $66.6 \%$. This result agrees with over all prevalence, $61.98 \%$, reported and Derese (2013) in Humbo district but it is in comparable with over all prevalence, $25.6 \%$, reported by Belew and Mekonnen (2011) in and Around Holeta Town. In former case the agreement in result may be due to similarity in management system, extensive management system, in which sample was taken but in later case difference in result may be due to management system, semi extensive farming system in addition to extensive farming system, from which sample was taken.

The type of tick species identified in the area during the study period from November 2013 to April 2014 are Rhipicephalus everts evertsi, Amblyommacohaerence, A.variegatumand Boophilus decoloratus in their ascending order of abundance. Amblyomma was the most abundant tick genus in the area accounts (45.29\%) from 3287 ticks collected during the study period, and followed by Boophilus which accounts for (40.34\%) of total tick collection. The $3^{\text {rd }}$ places were taken by Rhipicephalus (14.35\%).

B.decoloratus was identified as the most abundant tick species in the study area constituting $40.34 \%$ of total tick collection. Almost Similar result $(41.4 \%)$ was reported by (Vincenzo et al., 2013) in Nigeria in which Rhipicephalus (Boophilus) decolaratus was the first most abundant tick species in their study. This finding is consistent with the findings of Yismashewa (2005) who reported mainly in low and highland areas during early rainy season (March to April). This is in agreement with Sileshi et al., (2007) as described that B.decolaratus is the commonest and most wide spread tick in Ethiopia collected in all administrative regions except in the Afar region. However, this finding is different with the findings of Tamru (2008) at Asela and Teshome et al., (1995) reported that the highest prevalence of B.decolaratus (80\%) in the study areas. According with Shiferaw (2005) B.decolaratus is highest in frequency observed during dry seasons (January, February and early March) in Wolaita zone.

This result is disagreed with the finding of Alekaw (1998) at Metekel Ranch, Ethiopia showing prevalence of $5.7 \%$. This may be due to the geographical location and altitude factors which is 1500 to 1600 meter above sea level of Metekel Ranch. This species is reported to be widely distributed in the central rift valley parts of Ethiopia Pegra et al., (1981), Dhuffera (1997) and Gashaw (2004) also recorded higher number of
Boophilus in areas with high rainfall. It is also prevalent in many other parts of Ethiopian rift valley (Solomon and kayaa, 1998), Bale (Dejenu, 1988) North wolloSeyoum (2001) and highland areas of Harar and Diredawa districts (Mannueri and Tilahun, 1991). Morel (1980) stated that Rhipicephalus (Boophilus) decolaratus often collected in Ethiopia and does not seen really abundant anywhere. According to Bekele (2002) relative abundance of Rhipicephalus (Boophilus) decolaratus increases from low land towards highland. The females were abundant from September to April and transmit Babesiabigemina to cattle, and severe infestation can lead to tick worry, anorexia and anemia (Seyoum, 2005). The one-host ticks of the genus Boophilus that parasitize ruminants represent a hindrance to livestock farming in tropical and sub-tropical countries. They transmit the causative agents of anaplasmosis ("gall sickness") and Babesiosis ("red water") in cattle (Walker et al., 2003).

The study conducted in Wolaita zone by Dessie and Getachew (2006) agree with current study showing that A.variegatum was the second abundant tick species at highland and midland, and the first abundant in the lowland during wet period. This variation may be due to the changing of environmental condition with the result of global warming that highly affect the ecology of ticks. The similarity in result was may be due to the geographical location where A.variegatum found in highest number in the highland and high rainfall and also due to its being relatively active throughout the year in most part of Ethiopia.

Ambylomma cohaerence was the third abundant tick species $(17.60 \%)$ in the study area. This finding is consistent with, Derese (2013) in Humbo district, Dessie and Getachew (2006) in Wolaita zone with significant seasonal distribution variation at highland and lowland, Belew and Mekonnen (2011) in Holeta, and Tessema and Gashaw (2010) in Assella. This result disagrees with Sileshiet al., 2001 and De Castro, 1994 has reported it is the most abundant tick species in Maji (Kefa) in South. This result also disagrees with reports of (Seid, 2004) with the prevalence of $50.5 \%$. The distribution of A.cohaerenceis generally between an altitude of about 1200-1500 m.a.s.l with annual rainfall of about 625-1500 $\mathrm{mm}$. This result disagreed with tick survey conducted in Western Ethiopia, Jimma (Yitbarek, 2004) which was found to be the most prevalent in the area with the prevalence of $83.1 \%$. The prevalence of A.cohaerence is alarmingly important as this tick has been reported as a vector for Cowdriarum inantium which is the causative agent of cowdriosis ("heart water") (Sileshi et al., 2007). 
This study showed that except B.decoloratus the number of male is greater than female which agree with previous report (Solomon et al., 2007 and Mesele, 1989). This is due to the fact that fully engorged female ticks drop off to the ground to lay eggs while males tend to remain on the host up to several months then continue feeding and mating with other females. The period of female attach on the host relatively less than male (Solomon et al., 2001). The females of B.decolaratus outnumbered males in this study probably due to small size of male which may not be seen during collection (Tessema and Gashaw, 2010).

In this present study, different animal related risk factors were studied to determine whether there is a significant variation in tick infestation between and among different groups of animals with suspected risk factors. In this study the difference on tick prevalence (Table: 3) was found to be statistically in-significant $(\mathrm{P}>0.05)$ which was higher in age groups greater than $4(43.60 \%)$ and is less in age groups less than or equal to $4(23.00 \%)$. Young's are less infected than higher age groups.

The proportion of tick infestation was higher in poor body conditioned as compared to medium body conditioned and good body conditioned animals. As report by Bilkis et al., (2011) in Bangladesh shows higher tick infestation rate was seen in poor body conditioned animals than the other two. This was due to poor body conditioned animals are less resistant to tick infestation and lack enough body potential to build resistance with age advancement.

The result of current study shows that the presence of high tick infestation in exotic breeds than local and cross breeds. In the past, attempts to introduce cattle of exotic inheritance into tropics have not had success expected. One reason for the failure could be because of the high susceptibility to ticks and TBDs of exotic and cross breeds. However, the fear of introducing susceptible cattle can be solved by introducing certain degree of resistance in these cattle by means of prophylactic treatment before introducing into enzootic areas (Solomon et al., 2001).

In this short period of study, it was possible to indicate the trend seasonality of tick population by comparing the number of tick collected every month. From November to April, the number of tick population has been shown variation in decreasing manner. This is probably due to changes in climatic condition from slightly wetter month (November) to the slightly drier month (April). Similarly the comparable report has been conducted by Feseha (1983), Alekaw (1998), Solomon et al. (2001), Seid (2004) and Hussein (2004) and a similar survey has also been reported by Gezali (2010) that infestation by ticks during the dry months reaches very low level and during the rainy season the activity of adult tick become high.

Conclusion and recommendations are as follows:

The study on the identification of tick species and its distribution in the area is considered as an aid of improving tick control. Among ectoparasites ticks cause greatest economic loss in livestock production either by transmitting a wide variety of tick borne diseases or by affecting the health of animal as well as the quality of hides and skins. The study further presents the tick species identified in their veterinary value; the most important and abundant tick species identified were R.evertsievertsi, A.cohaerence, A.variegatum and B.decoloratus and in their ascending order. The study showed that little attempts were made to control the infestation of tick in the area. The ecological and environmental factors play a role in distribution of tick and the prevalence of TBDs. Acaricide application is the main tick control method in the study area. B.decoloratusis the most abundantly distributed tick species in the study area. They transmit the causative agents of anaplasmosis ("gall sickness") and Babesiosis ("red water") in cattle (Walker et al., 2003).

Therefore, effective tick control program should be formulated and implemented based on the distribution pattern of ticks and factors responsible for their distribution. In line with the above conclusions the following recommendations were forwarded: Attention should be given to the control of the identified tick species which are common in the study area (Amblyomma variegatum and Boophilus decoloratus). Proper use of acaricide should be carried out, Detection of acaricide resistance tick species which are economically important since limited types of acaricides were used in the area and Further investigation should be done in the area to identify other species in the area and to understand their seasonal dynamics.

\section{References}

Abebaw, G. (2004): Seasonal dynamics and host preference of Boophilus decolaratuson naturally infested cattle in Jimma zone, South Western Ethiopia. Ethiopia Vet.J.18 (1):19-28. 3. 
Alekaw, S. 2000. Distribution of ticks and tick borne diseases at Metekel Ranch. Journal of Ethiopian Veterinary Association 4(1), 40-60.

Aerts, J.M., and Neshem, O.N., 1999. Florida beef cattle external pest control survey. UF Pesticide Information Office: Report in Production. http://Edis. Ifas.ufl.edu/pdf files/PI/P104300.pdf.

Amanuel, T. (1982). Animal evaluation of the feeding value of sisal waste (agave sisaline). M.Sc. thesis, Alemaya University of agriculture (AUA), Alemaya, Ethiopia.Pp.3137.

Bansal, G.C., 2005. Bovine theileriosis in India: an overview. Proc. Nat. Acad. Sci. India, 75: 134-43

Befekadu, D. and Berhanu, N. (2000). Annual report on the Ethiopian economy.Vol.1, 1999/2000.The Ethiopian economic association, Addis Ababa, Ethiopia.Pp.429.

Behailu, A., 2004. A survey of ticks and TBDs in cattle in Arsi zone, DVM Thesis, FVM, AAU, Ethiopia.

Belew, T., and Mekonnen, A., 2011. Distribution of Ixodidae ticks on cattle in and around Holeta Town, Ethiopia. Global veterinarian, 7(6):527-531.AAU, Ethiopia.

Bianchi, M.W., Barre, V. and Messd, S., 2003. Factors related to cattle infestation level and resistance to acaricides in Boophilusmicroplus tick populations in New Calender. Vet.Parasitol.112: 75-89.

Bilkis, M. F., Mondal, M. M., Rony, H. Sa. Islam1 M. A. and Begum, N., 2011. Host determinant based prevalence of ticks and lice in Cattle (Bos indicus) at bogra district of Bangladesh. Department of Parasitology, Bangladesh Agricultural University Mymensingh-2202, Bangladesh.Prog. Agri., 22: 1 \& 2, Pp $65-73$.

Byford RL, Craig ME, Crosby BL. A review of ectoparasites and their effect on cattle production. J AnimSci 70:597-602, 1992.

CSA, 2013.Agricultural Sample Survey, Volume II. Report on Livestock and Livestock characteristic, Addis Abeba, Ethiopia, Pp 1-10.

De Castro JJ (1997). Sustainable tick borne diseases control in Western Ethiopia. J. S. Afr. Vet. Assoc. 71(4):240-243.

Drummond, R.O. 2007. Tick borne livestock diseases and their vector. World Animal Review 3.htm.

Dessie, S., and Getachew, A., (2006). Cattle tick dynamics in different agro-ecological zones of Wolayta, Southern Ethiopia. Ethiopia vet J.10(2):85-99.

Daniel, W., 1994. Survey on ticks species of cattle, camel, sheep and goats in south wollo region
Ethiopia. DVM thesis, Faculty of Veterinary Medicine, AAU, Debrezeit.

De Castro, J.J., 1997. Sustainable tick borne diseases control in Western Ethiopia. J. S. Afr. Vet. Assoc., 71: 4, 240-243.

Dejenu, G., 1988. A preliminary survey of ticks on domestic animals in Bale.Faculty of Veterinary Medicine, AAU, Debrezeit, Ethiopia.

Dessie, S., 2005.Cattle Tick Dynamics in Different Agro-Ecological Zones of Wolayta, Southern Ethiopia.MSc thesis, Addis Ababa University, Faculty of Veterinary Medicine, Debre Zeit, Ethiopia. Pp 18-83.

Dhuffera, W., 1997. Survey of ticks and tick borne diseases in domestic animals in and around Debrezeit, Eastern. DVM thesis, AAU, Faculty of Veterinary Medicine, Pp 1-79.

FAO (2004): Resistance management and integrated parasite control in ruminants. FAO and Agr.Org.Of the United Nations, Rome.Pp.9-77.

Feseha, B., 1997. Species composition and distribution of Ixodidticks in Eastern Hararghe, Ethiopia. Agri.sci.16:37-51

Feseha, G. (1983). Notes on tick species and tick borne diseases of domestic animals in Ethiopia. FVM, AAU, Ethiopia, Pp. 1-64.

G/Michael, T., 1993. Ticks and tick born disease of cattle in North omo zone, DVM thesis, Addis Ababa University, Faculty of veterinary medicine, Debrezeit. Pp 150.

Gulilat A. (1987). Survey of Ticks on domestic animals in Hararghe Administrative region. DVM thesis, Faculty of Vet. Medicine, Addis Ababa University, Debrezeit, Ethiopia.Pp.28-32.

Hendrix, C.M., 1998. Diagnostic Veterinary parasitology, $2^{\text {nd }}$ ed. Mosby, Inc. Pp $164-227$.

Hoogstraal, H. (1956). African Ixodidae, Vol.I, ticks of Sudan. Pp. 87-107. Ticks of Sudan (with special reference to Equatorial province and with preliminary reviews of genera Boophilus. Margaropus, Hyalomma). Res.rep.N.M.005 050.29.07. U.S.Govt.Dept.of navy, Bur.Med.Surg., Washington, D.C.Pp.5-912.

Hoogstraal H. The epidemiology of tick-born CrimeanCongo hemorrhagic fever in Asia, Europe and Africa. J Med Entomology 1979; 15:307.

Hussen, Y., 2009. Preliminary survey of cattle tick species and burden in and around Bako Town. DVM Thesis, school of Veterinary Medicine Jimma University, Jimma, Ethiopia.

Jongejan F, Uilenberg G: The Global importance of ticks. Parasitology 2004, 29 (Supp):S13-S14. 
Kassa. B. (2005): Standard veterinary laboratory diagnostic manual. Vol. III. MOA Addis Ababa, Ethiopia

Kettle DS (1995). Medical and Veterinary Entomology. 2nd Ed. UK: CAB international pp. 420-460.

Lakew, D., Menale, K., Benin, S. and PENDER 1. (2000). land degradation and strategies for sustainable development in the Ethiopian highlands; Amhara region. Socioeconomics and policy research working paper 32.ILRI, Nairobi, Kenya.pp.122.

Lefebvre PC, Blancou J, Chermette R, Uilenberg G (2010). Infectious and Parasitic diseases of livestock. 1:93-128.

LORD, C.C. (2008). Brown dog tick, Rhipicephalus sanguineous Latreille (Arachnida: Acari: Ixodidae). Featured Creatures from Entomology and Nematology Department.

Manueri, K. K. and Tilahun, J., 1991.A survey of ectoparasites of cattle in Harar and Dire Dawa districts, Hararghe administrative region of Ethiopia. Bull. Anim. Hlth. and Prod.In Afr., 39: 1524.

Mehari, B., 2004. Distribution of livestock tick species in Awassa Area. DVM Thesis, Faculty of Veterinary Medicine, Addis Ababa University, Debre Zeite, Ethiopia.

Mekonnen, S. (1998): Ticks, ticks born disease and control strategies in Ethiopia, proceeding the second international conference on tick born pathogen at the host-vector interference global perspective August 20-September 1995, Kruger National Park, South Africa.

Mesele, A., 1989. Bovine tick survey in Bahir darAwraja. DVM thesis, Faculty of Veterinary Medicine, AAU, Debrezeit. Pp 1-40.

Minjauw B, McLeod A (2003). Tick borne diseases and poverty. The impact of ticks and tick borne diseases on livestock owners in India and Eastern health program center for tropical veterinary medicine, University of Edinburgh, UK pp. 24-57.

Minjauw B, McLeod A (2003). Tick borne diseases and poverty. The impact of ticks and tick borne diseases on livestock owners in India and Eastern health program center for tropical veterinary medicine, University of Edinburgh, UK pp. 24-57.

Morel, P.C. (1980). Study on Ethiopia ticks. Pp.180-337.

Nicholson, M. J. and Butterworth, M. H. (1986): A guide to condition scoring of zebu cattle, international livestock center for Africa. Addis Ababa, Ethiopia.

Niyonzema, A. and H.H. Kiltz, 2007.Control of ticks and tick-borne diseases in Burundi. ACIAR Proc., 17: 16-7.
Norval, R.A.I., B.H. Fivaz, J.A. Lawrence and A.F. Brown, 2007.Epidemiology of tick-borne diseases of cattle in Zimbabwe. Trop. Anim. Hlth. Prod., 16: 63-70.

Naser, M., 1985. Common tick species in Wolayta Awraja, DVM, thesis, Addis Ababa university, Faculty of veterinary medicine, Debrezeit, Pp 1-38.

Nkululeko, N., 2007. The geographic distribution of ticks in the eastern region of the Eastern Cape Province. Department of veterinary tropical disease faculty of veterinaryscience. University of Pretoria. Pretoria.

Derese,D, 2013. Study on Prevalence and identification of ixodid ticks of bovine in Humbo district, of Wolayta Zone SNNPR,DVM thesis, Haramaya University, College ofVeterinary Medicine, Haramaya, Ethiopia.

Pegram, RG, Hoogstraal $H$. and Wassef H.Y. (1981).Ticks (acarida, ixodidae) of Ethiopia. Distribution, ecology, and host relationship of species infesting livestock. Bulletin of entomological research (71): 339-59.

MoranPG, MC, Nigarura G (2004). Tick control: New concepts, www.fao.org/AGA/AGAP/FRG/ Feedback.htm.

Sharma, S.N., Gahlot, A.K., and Tanwar, R.K., 2003. Veterinary Jurisprudence. $5^{\text {th }}$.ed. NBS Publishers, India.Pp.128-129.

Seid, B., 2004. Survey of cattle tick species in and Around MizanTaferi, Bench Maji zone of SNNPS, DVM Thesis, Faculty of Veterinary Medicine, Addis Ababa University, Debreziet, Ethiopia.

Seyoum, Z., 2001. Study of tick and TBDs on cattle at Girran valley in:the North Wollo Zone. Proceeding of the Ethiopian Vet. Assoc. Pp. 15.

Seyoum, Z., 2005. Distribution and host parasite relationship of Ixodidsticks in Eastern Amhra, Kombolcha Regional Veterinary Laboratory, Kombolcha, Ethiopia Pp. 34-47.

Shiferaw, D., 2005. Cattle tick dynamics in different agro-ecological zones of Wolayta, Southern Ethiopia. Master degree thesis. Faculty of Veterinary Medicine, Addis Ababa University, Debre Zeite, Ethiopia Pp. 1-137.

Sileshi, M., Pegram, R.G., Solomon, G., Abebe, M., Yilma, J. and Sileshi, Z., 2007. A synthesis of review of Ixodids (Acari: Ixodidae) and Argas (Acari: Argasidae) ticks in Ethiopia and their possible role in diseases transmission. Ethio. Vet. J., 2: $1-22$.

Sileshi, M., 2001.Ticks, tick-borne disease and their control in Western Ethiopia.Insect Science. Applic.13: 661-664. 
Solomon G, Kaaya GP (1996). Studies on the developmental and survival of Rhipicephaluspulcheluand Amblyomagemmaunder field condition.Ethiopian Veterinary Association.

Solomon .G,Kassaye.G, P.Feseha, G., Teferi, G. and Getachew,T.(1998): Ticks and tick borne diseases associated with indigenous cattle in Didtuyura Ranch, Southern Ethiopia.inseSic,Apliec. (18): 5966

Solomon. G, Nigist, M., and Kassa. B. 2001. Seasonal variation of ticks on calves at Sebeta in western Shewa Zone.Ethiopian Veterinary Journal, 7 (1\&2): 17-30.

Solomon, G., Sileshi, M., Kaaya, G. P., Tilahun, T., Yilma, J., 2004.Prevalence of Ixodid ticks and Trypanosomosis in camels in southern Ethiopia.Ethio. Vet. J., 8: 2, 23.

Southerest, R.W., 1983. Management of Arthropods and Parasitism in Livestock.In:TropicalParasitosis and Parasitic Zoonoses, Dunsmare, J.P. (Ed.). Murdon University, Perth, Australia, Pp: 41-56.

Taylor MA, Coop RH, Wall RL (2007). Veterinary Parasitology.3rd Ed. Black Well Publishing, London Pp. 679-712.

Surafel, M., 1996.Survey of tick species of four domestic animals in Tigray region.DVM thesis, Faculty of Veterinary Medicine, AAU, and Debrezeit, Ethiopia.

Tamru, T., 2008. Survey of Bovine tick species in and around Asela Town, DVM Thesis, School of Veterinary Medicine, Jimma University, Jimma, Ethiopia

How to cite this article:

Dereje Darza, Asrat Ayza and Birhanu Lencha Kiffo. 2021. Study on Prevalence and Major Species Identification of Ixodidae Ticks of Bovine in Soddo Zuria Districts of Wolayta Zone in Southern Nation Nationalities and People's Region. Int.J.Curr.Res.Aca.Rev. 9(01), 70-80.

doi: https://doi.org/10.20546/ijcrar.2021.901.006
Tesfaye .A. (1990). Livestock development in the peasant sector of highlands of Ethiopia: some policy issues and implications, ILCA, Addis Ababa, Ethiopia.97140. https://www.google. Tick photos $\mathrm{com} / \mathrm{search}$. Accessed on (05/12/2014).

Thrust field, M (2005) Veterinary epidemiology $3^{\text {rd }}$ ed. Black well science Ltd, London.Pp.32

Vincenzo, L., Kim. P., Barend, B., Ayodele, M., Charles, D., Gyang, B., Augustine. I and Susan.W, 2013.Ixodid ticks of traditionally managed cattle in central Nigeria: where Rhipicephalus (Boophilus) microplus does not dare. Parasit.Andvect.6:171.

Yehualashet, T, Gebra, F, Wakjira, A. and Tsega, T. (1995): Preliminary observation on ticks, seasonal dynamics and resistance of three indigenous and cross breed cattle in Ethiopia. Bulletin of Animal Health and Production in Africa, (43):114

Young, A.S., Groocock, C.M. and Karuki, D.P. (1998): Integrated control of ticks and tick borne disease of cattle in Africa, parasitol, Pp. 403-432.

Walker AA, Bouatour A, Camicas JL, Estadapena AA, Harok IG, Hatif AA, Pegram RG, Preton PM (2003). Ticks of domestic animals in Africa: A guide to identification species. The University of Edinburgh, UK pp. 67-80.

Wolayta Soddo District Agricultural Development Office (WSDADO), 2013. Annual report on total livestock population, weather and climate of the Wolayta Soddo District, Southern Ethiopia. 